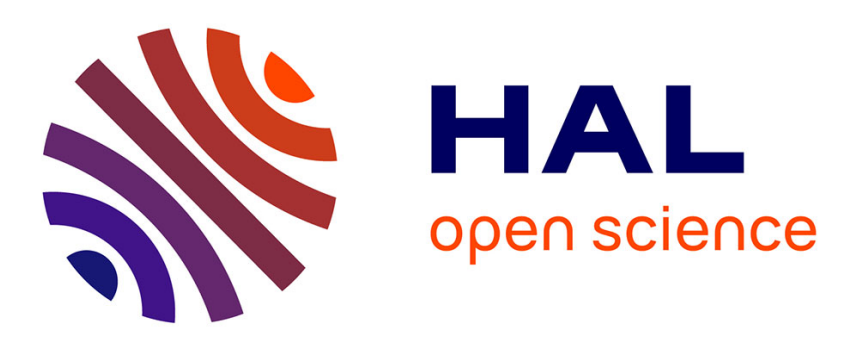

\title{
Atomic Layer-by-Layer Epitaxy of Silicon and Germanium Using Flash Heating in CVD
}

J. Murota, M. Sakuraba, T. Watanabe, T. Matsuura, Y. Sawada

\section{To cite this version:}

J. Murota, M. Sakuraba, T. Watanabe, T. Matsuura, Y. Sawada. Atomic Layer-by-Layer Epitaxy of Silicon and Germanium Using Flash Heating in CVD. Journal de Physique IV Proceedings, 1995, 05 (C5), pp.C5-1101-C5-1108. 10.1051/jphyscol:19955130 . jpa-00253827

\section{HAL Id: jpa-00253827 https://hal.science/jpa-00253827}

Submitted on 1 Jan 1995

HAL is a multi-disciplinary open access archive for the deposit and dissemination of scientific research documents, whether they are published or not. The documents may come from teaching and research institutions in France or abroad, or from public or private research centers.
L'archive ouverte pluridisciplinaire HAL, est destinée au dépôt et à la diffusion de documents scientifiques de niveau recherche, publiés ou non, émanant des établissements d'enseignement et de recherche français ou étrangers, des laboratoires publics ou privés. 


\title{
Atomic Layer-by-Layer Epitaxy of Silicon and Germanium Using Flash Heating in CVD
}

\author{
J. Murota, M. Sakuraba, T. Watanabe, T. Matsuura and Y. Sawada \\ Laboratory for Electronic Intelligent Systems, Research Institute of Electrical Communication, Tohoku \\ University, 2-1-1 Katahira, Aoba-ku, Sendai 980-77, Japan
}

\begin{abstract}
Atomic layer-by-layer epitaxy control of $\mathrm{Si}$ and $\mathrm{Ge}$ in flash-heating $\mathrm{CVD}$ using $\mathrm{SiH}_{4}$ and $\mathrm{GeH}_{4}$ gases was investigated. Sclf-limiting $\mathrm{SiH}_{4}$ reaction on the $\mathrm{Ge}$ surface results in $\mathrm{Si}$ atomic-layer formation at substrate temperatures below $300^{\circ} \mathrm{C}$ even without the flash heating. In the case of Ge growth, by increasing the flash light intensity and the $\mathrm{GeH}_{4}$ partial pressure, $\mathrm{Ge}$ atomic-layer growth on the wet-cleaned $\mathrm{Si}(100)$ was achieved with a single flash shot at $275^{\circ} \mathrm{C}$. Using these growth controls, resonant tunneling diodes of $\mathrm{Ge} / \mathrm{Si}_{1} \mathrm{Ge}_{1}(50 \AA) / \mathrm{Ge}(50 \AA)$ $/ \mathrm{Si}_{1} \mathrm{Ge}_{1}(50 \AA) / \mathrm{Ge}$, in which the $\mathrm{Si}_{1} \mathrm{Ge}_{1}$ layers were formed by alternately depositing single atomic-layers of $\mathrm{Si}$ and $\mathrm{Ge}$, were fabricated, and clear negative resistance in the current-voltage characteristic was observed at $10 \mathrm{~K}$. The current peaks were expected to be assigned to a hole resonant tunneling via light-hole bound state in the Ge quantum well. This fact suggests that the diode structure has abrupt $\mathrm{Si}_{1} \mathrm{Ge}_{1} / \mathrm{Ge}$ interfaces by employing a lowtemperature atomic layer-by-layer growth process below $300^{\circ} \mathrm{C}$.
\end{abstract}

\section{INTRODUCTION}

Atomic layer-by-layer epitaxy control of $\mathrm{Si}$ and Ge by chemical vapour deposition (CVD) is attractive to create novel functional nano-structures and superlattice structures by alternately depositing single atomic-layers of the different elements. In order to achieve atomic-layer epitaxy control, it is important to separate the adsorption and reaction of reactant gases. A self-limiting process using metal organic or chloride gases has been employed in atomic-layer epitaxy [1-4]. However, in order to prevent any contamination into deposited films, simple hydride gases such as $\mathrm{SiH}_{4}$ and $\mathrm{GeH}_{4}$ without carbon or halogen should be used as a reactant gas. In our previous work [5-8], the separation hetween the surface adsorption and the reaction of $\mathrm{SiH}_{4}$ on $\mathrm{Si}$ or $\mathrm{GeH}_{4}$ on $\mathrm{Ge}$ was achieved using a flash-heating CVD system, where the reactant molecules adsorbed on the surface were decomposed by the Xe flash lamp light shots with an intensity of $20 \mathrm{~J} / \mathrm{cm}^{2}$. These results give information about $\mathrm{SiH}_{4}$ adsorption on $\mathrm{Si}$ and $\mathrm{GeH}_{4}$ adsorption on $\mathrm{Ge}$. However, adsorption processes of $\mathrm{SiH}_{4}$ on the $\mathrm{Ge}$ surface and $\mathrm{GeH}_{4}$ on the Si surface in the initial growth stages should be studied for atomic layer-by-layer control in the formation of superlattice structures.

In the present work, single atomic-layer growth of $\mathrm{Si}$ on the Ge surface and of $\mathrm{Ge}$ on the $\mathrm{Si}$ surface were investigated and a resonant tunneling diode of $\mathrm{Ge} / \mathrm{Si}_{1} \mathrm{Ge}_{1}(50 \AA) / \mathrm{Ge}(50 \AA) / \mathrm{Si}_{1} \mathrm{Ge}_{1}(50 \AA) / \mathrm{Ge}$ structure was fabricated. 


\section{EXPERIMENTAL}

Single atomic-layer growth of $\mathrm{Si}$ and $\mathrm{Ge}$ were carried out by use of $\mathrm{SiH}_{4}$ and $\mathrm{GeH}_{4}$ gases, respectively, in an ultraclean if-heated, cold-wall low-pressure CVD system as schematically shown in Figure 1 [5-8]. The typical process sequence of the flash-heating CVD is shown in Figure 2. The flash light duration was about $1 \mathrm{~ms}$ and the intensity was varied from 20 to $60 \mathrm{~J} / \mathrm{cm}^{2}$. The substrates used were p-type Si wafers of 2-20 $\Omega \mathrm{cm}$ with mirror-polished (100) surface, and they were cleaned in a $4: 1$ solution of $\mathrm{H}_{2} \mathrm{SO}_{4}(98 \%)$ and $\mathrm{H}_{2} \mathrm{O}_{2}(30 \%)$ followed by a rinse in high purity deionized (DI) water in several cycles, and a $2 \% \mathrm{HF}$ solution followed by a final rinse in DI water (hereafter referred as wet-cleaned Si(100)), before loading the substrates into the load-lock chamber. As the substrate for $\mathrm{Si}$ growth on the Ge surface, a $400 \AA$-thick $\mathrm{Ge}$ epitaxial film was deposited by thermal decomposition of $\mathrm{GeH}_{4}$ at $350^{\circ} \mathrm{C}$ on the wet-cleaned $\mathrm{Si}(100)$ substrate [9], and it was cleaned in a $2 \% \mathrm{HF}$ solution with a final rinse in DI water (hereafter referred as wet-cleaned $\mathrm{Ge}(100)$ ). Thicknesses of the $\mathrm{Si}$ and $\mathrm{Ge}$ films were measured by a step profiler. The ultrathin film thicknesses of $\mathrm{Si}$ on the Ge surface and Ge on the Si surface were also estimated by $x$-ray photoelectron spectroscopy (XPS). The fabrication process of resonant tunneling diode of $\mathrm{Ge} / \mathrm{Si}_{1} \mathrm{Ge}_{1}(50 \AA) / \mathrm{Ge}(50 \AA) / \mathrm{Si}_{1} \mathrm{Ge}_{1}(50 \AA) /$ Ge structure is detailed in Section 3.3 .

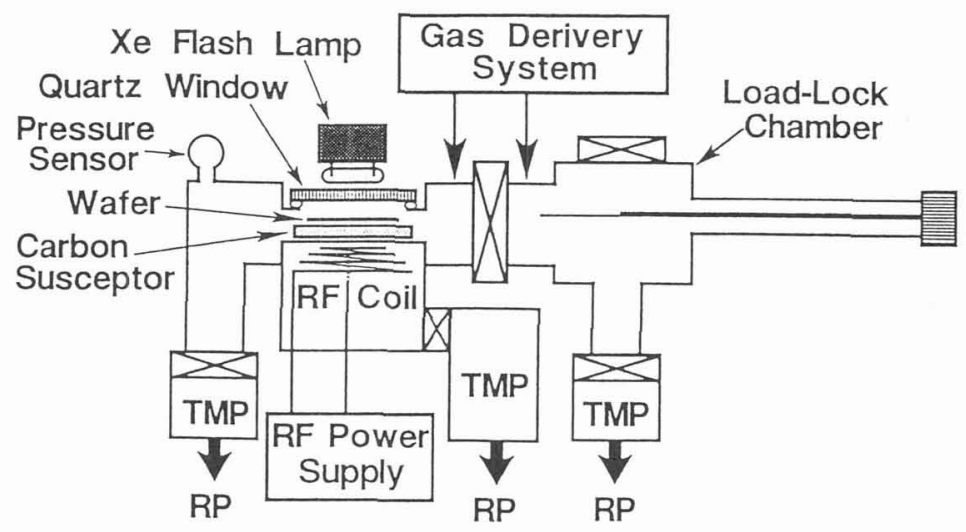

Figure 1: Schematic diagram of the ultraclean if-heated cold-wall low-pressure CVD system with a Xe flash lamp.

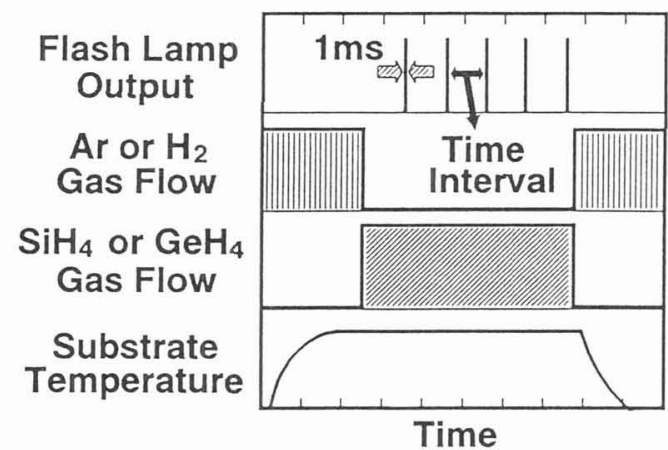

Figure 2: Typical process sequence of the flash-heating CVD after the samples were placed on the susceptor in the reactor. 


\section{RESULTS AND DISCUSSION}

\subsection{Single Atomic-Layer Growth of Si on the Ge surface}

Figure 3 shows the $\mathrm{SiH}_{4}$ exposure time dependence of the $\mathrm{Si}$ film thickness deposited on the wet-cleaned $\mathrm{Ge}(100)$ without the flash shot. It is found that a Si film is thermally deposited on the Ge surface even at temperatures below $385^{\circ} \mathrm{C}$, where the continuous thermal reaction on the Si surface scarcely occurs [5,6]. At $200-300^{\circ} \mathrm{C}$, it is found that the deposited $\mathrm{Si}$ film thickness increases with increasing $\mathrm{SiH}_{4}$ exposure time and saturates to the single atomic-layer thickness, i.e., the $\mathrm{SiH}_{4}$ reaction rate on the initial

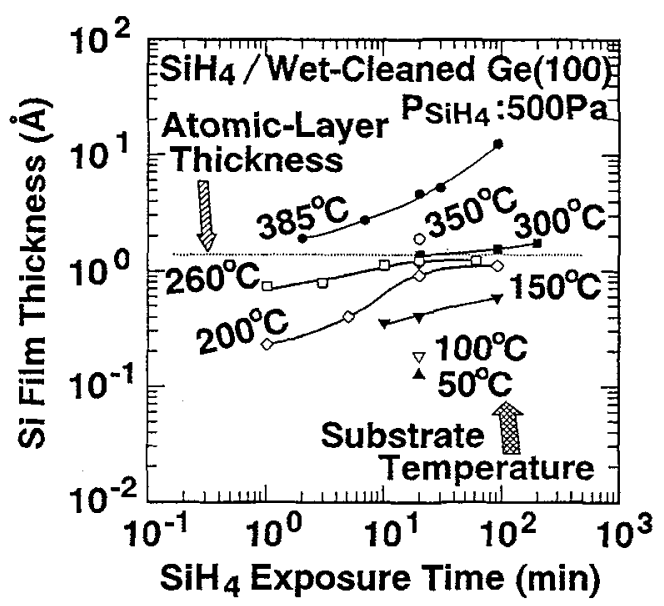

Figure 3: $\mathrm{SiH}_{4}$ exposure time dependence of the $\mathrm{Si}$ film thickness deposited on the wet-cleaned $\mathrm{Ge}(100)$ at various substrate temperatures without the flash shot. The $\mathrm{SiH}_{4}$ partial pressure was $500 \mathrm{~Pa}$. Prior to exposing the wet-cleaned $\mathrm{Ge}(100)$ to $\mathrm{SiH}_{4}$ environment, it was heated for 40 minutes in $\mathrm{H}_{2}$ environment of $290 \mathrm{~Pa}$ at $260^{\circ} \mathrm{C}$, where the single atomic layer-by-layer epitaxy of $\mathrm{Ge}$ on the Ge surface was realized by using the flash-heating CVD $[7,8]$.

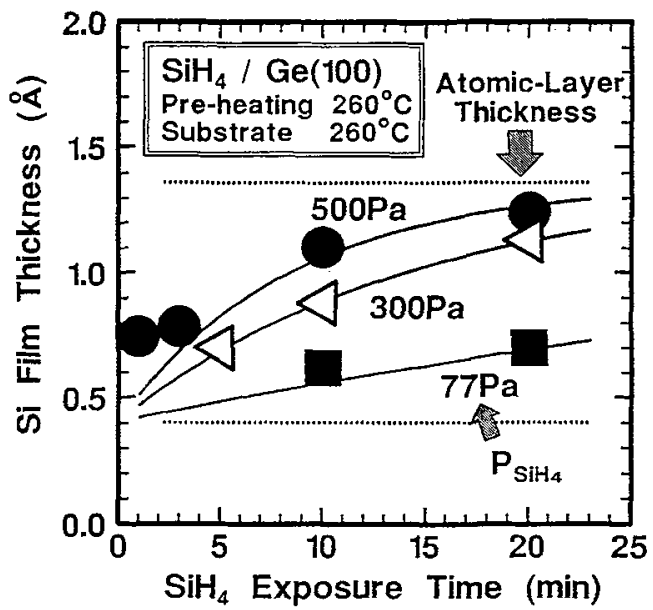

Figure 4: $\mathrm{SiH}_{4}$ exposure time dependence of the $\mathrm{Si}$ film thickness deposited on the wet-cleaned $\mathrm{Ge}(100)$ at various $\mathrm{SiH}_{4}$ partial pressure without the flash shot. The substrate temperature was $260^{\circ} \mathrm{C}$. Prior to exposing the wet-cleaned $\mathrm{Ge}(100)$ to $\mathrm{SiH}_{4}$ environment, it was heated for 40 minutes in $\mathrm{H}_{2}$ environment of $290 \mathrm{~Pa}$ at $260^{\circ} \mathrm{C}$. The solid curves are calculated from Equation (1) with $k_{\mathrm{GeH} 4}=1.3 \times 10^{-5} \mathrm{~Pa}^{-1} \mathrm{~s}^{-1}$. 
Ge surface is much larger than that on the Ge surface covered with a single atomic-layer of Si. This may be caused by change of the hydrogen adsorbed surface structure $[10,11]$. At $385^{\circ} \mathrm{C}$, the Si film thickness increases continuously beyond the single-atomic layer thickness. This is considered to be caused by the reaction of $\mathrm{SiH}_{4}$ at $\mathrm{Ge}$ atoms segregated on the top surface, although $\mathrm{Ge}$ segregation was reported only at higher temperatures [12]. The surface segregation of $\mathrm{Ge}$ atoms would result in degradation of the abruptness of the $\mathrm{Si} / \mathrm{Ge}$ heterointerface. Therefore, the deposition process below $\sim 300{ }^{\circ} \mathrm{C}$, where the surface segregation does not proceed, is necessary.

Figure 4 shows the $\mathrm{SiH}_{4}$ exposure time $(t)$ dependence of the Si film thickness deposited on the wetcleaned $\mathrm{Ge}(100)$ without flash shot at various $\mathrm{SiH}_{4}$ partial pressures. Substrate temperature is $260{ }^{\circ} \mathrm{C}$. When the experimental data plotted in Figure 4 were normalized to $\left(P_{\mathrm{SiH} 4} \cdot t\right)$ dependence, they were very closely located on the single curve and the thickness at $\left(P_{\mathrm{SiH} 4} \cdot t\right) \sim 0$ was around $0.4 \AA$ with little dependence on $P_{\mathrm{SiH} 4}$. Therefore, two-step process, in which there were a fast step and a slow step in reaction kinetics, was distinguished. Assuming that the initial fast growth step with a thickness $\left(d_{\mathrm{i}}\right)$ proceeded in a short time within a minute, the second step thickness $\left(d_{S}\right)$ can be fitted into Langmuir type adsorption equation:

$d_{\mathrm{S}}=\left(d_{\mathrm{Si}}-d_{\mathrm{i}}\right)\left\{1-\exp \left(-k_{\mathrm{SiH} 4} P_{\mathrm{SiH} 4} t\right)\right\}$,

where $d_{\mathrm{Si}}$ is the single atomic-layer thickness of $\mathrm{Si}(100), k_{\mathrm{SiH} 4}$ the rate constant of $\mathrm{SiH}_{4}$ adsorption and $P_{\mathrm{SiH} 4}$ the $\mathrm{SiH}_{4}$ partial pressure. The solid curves in Figure 4 , calculated using the $k_{\mathrm{SiH} 4}$ value of $3.9 \times 10^{-6}$ $\mathrm{Pa}^{-1} \mathrm{~s}^{-1}$, are in very good agreement with experimental data. As far as initial step reaction kinetics, further investigation should be done.

\subsection{Single Atomic-Layer Growth of Ge on the Si surface}

Figure 5 shows the dependence of the Ge film thickness deposited on wet-cleaned $\mathrm{Si}(100)$ on the number of the flash shots. After the substrate has been once pre-heated up to $400^{\circ} \mathrm{C}$ in the reactor, the $\mathrm{Ge}$ single atomic-layer growth per shot is realized with the flash light intensity of $20 \mathrm{~J} / \mathrm{cm}^{2}$, as already reported at $260-275^{\circ} \mathrm{C}[7,8]$. Without pre-heating, on the other hand, the incubation period of Ge growth during a few hundreds of flash shots is observed with the flash light intensity of $20 \mathrm{~J} / \mathrm{cm}^{2}$. Since a dihydride

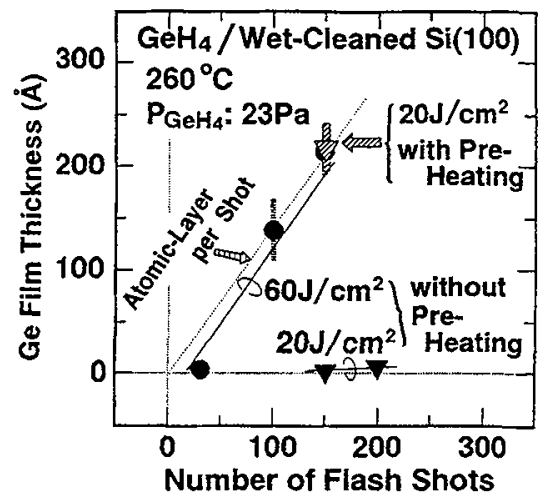

Figure 5: Dependence of the Ge film thickness deposited on the wet-cleaned $\mathrm{Si}(100)$ on the number of flash shots at $260^{\circ} \mathrm{C}$. The $\mathrm{GeH}_{4}$ partial pressure was $23 \mathrm{~Pa}$ and the shot to shot time interval $40 \mathrm{~s}$. 


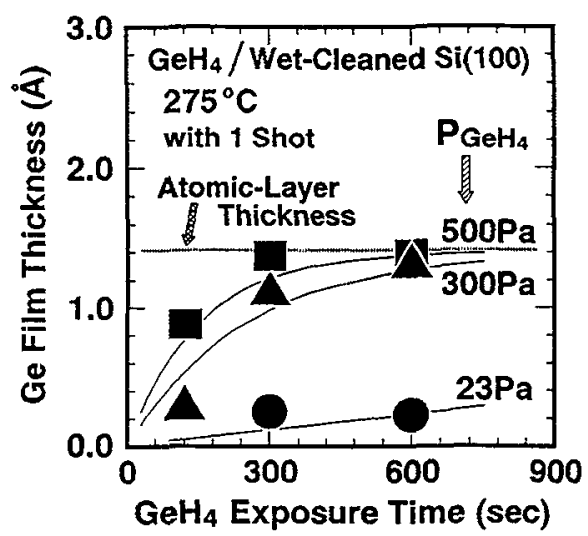

Figure 6: $\mathrm{GeH}_{4}$ exposure time dependence of the Ge film thickness deposited on the wet-cleaned $\mathrm{Si}(100)$ with a single flash shot at $275^{\circ} \mathrm{C}$ without the pre-heating. The flash light intensity was $60 \mathrm{~J} / \mathrm{cm}^{2}$. The solid curves are calculated from Equation (2) with $k_{\mathrm{GeH} 4}=1.3 \times 10^{-5} \mathrm{~Pa}^{-1} \mathrm{~s}^{-1}$.

phase of the $\mathrm{Si}(100)$ surface is transformed into a monohydride phase by heat treatment up to $\sim 400{ }^{\circ} \mathrm{C}$ as is well known [11], the above difference by pre-heating means that the adsorption of $\mathrm{GeH}_{4}$ molecules onto the Si surface and/or the reaction of the adsorbed $\mathrm{GeH}_{4}$ molecules on the Si surface by the flash light shot is dependent on the hydrogen coverage of the Si surface. From Figure 5, it is also found that the incubation period on the wet-cleaned Si surface is reduced to a few tens of shots by increasing the intensity up to $60 \mathrm{~J} / \mathrm{cm}^{2}$ even without the pre-heating. The incubation period hardly decreased by a repetition of additional 100 flash shots prior to an introduction of $\mathrm{GeH}_{4}$ gas into the reactor. This means that the flash shot scarcely induces the hydrogen desorption from the Si surface, i.e., the dihydride phase of $\mathrm{Si}(100)$ is not converted into the monohydride phase. Consequently, it is considered that the reaction between the adsorbed $\mathrm{GeH}_{4}$ molecules and the dihydride $\mathrm{Si}$ surface proceeds by the flash shots with the intensity of $60 \mathrm{~J} / \mathrm{cm}^{2}$.

Figure 6 shows the $\mathrm{GeH}_{4}$ exposure time dependence of the $\mathrm{Ge}$ film thickness deposited on wet-cleaned $\mathrm{Si}(100)$ with a single flash shot of $60 \mathrm{~J} / \mathrm{cm}^{2}$ at a substrate temperature of $275^{\circ} \mathrm{C}$ without pre-heating. It is found that the deposited Ge thickness tends to saturate to the single atomic-layer thickness with increasing the $\mathrm{GeH}_{4}$ exposure time and this results indicate that the surface adsorption site density is equal to the surface atom density. Therefore, it is assumed that all the adsorbed Ge containing species at the surface are decomposed perfectly by the flash shot of $60 \mathrm{~J} / \mathrm{cm}^{2}$. Then, the deposited thickness per shot $\left(d_{\mathrm{L}}\right)$ can be expressed by the Langmuir adsorption type equation $[5,6,8]$ :

$d_{\mathrm{L}}=d_{\mathrm{Ge}} \frac{k_{\mathrm{GeH} 4} P_{\mathrm{GeH} 4}}{k_{\mathrm{GeH} 4} P_{\mathrm{GeH} 4}+k_{-\mathrm{GeH} 4}}\left[1-\exp \left\{-\left(k_{\mathrm{GeH} 4} P_{\mathrm{GeH} 4}+k_{-\mathrm{GeH} 4}\right) t\right\}\right]$,

where $d_{\mathrm{Ge}}$ is the atomic-layer thickness of $\mathrm{Ge}(100), k_{\mathrm{GeH} 4}$ and $k_{-\mathrm{GeH} 4}$ the rate constants of $\mathrm{GeH}_{4}$ adsorption and desorption, respectively, $P_{\mathrm{GeH} 4}$ the $\mathrm{GeH}_{4}$ partial pressure and $t$ the $\mathrm{GeH}_{4}$ exposure time. Substituting the experimental data into Equation (2) and neglecting $k_{-\mathrm{GeH} 4}$ with $d_{\mathrm{Ge}}=1.4 \AA[5-8], k_{\mathrm{GeH} 4}$ is obtained to be $1.3 \times 10^{-5} \mathrm{~Pa}^{-1} \mathrm{~s}^{-1}$. The $k_{\mathrm{GeH} 4}$ value on the Si surface obtained here is much lower than that on the Ge surface $\left(8.3 \times 10^{-3} \mathrm{~Pa}^{-1} \mathrm{~s}^{-1}\right.$ at $\left.268^{\circ} \mathrm{C}[8]\right)$. As mentioned before, it is expected that the $\mathrm{GeH}_{4}$ adsorption is influenced by the different hydrogen adsorption structure of the Si surface from that of the Ge surface. 


\subsection{Fabrication of Resonant Tunneling Diode Using Atomic Layer-by-Layer Growth Control}

As shown in Sections 3.1 and 3.2, using $\mathrm{SiH}_{4}$ and $\mathrm{GeH}_{4}$ gases, self-limited control in single atomic-layer growth was realized. Resonant tunneling diodes, which contain a $50 \AA ̊-t h i c k$ Ge quantum well(QW) sandwiched by double barriers of $50 \AA$-thick $\mathrm{Si}_{1} \mathrm{Ge}_{1}$ atomic-layer superlattice on a relaxed Ge buffer layer, have been fabricated by using our atomic layer-by-layer epitaxy control method at $260-275^{\circ} \mathrm{C}$. Figure 7 shows the schematic cross section of the resonant tunneling diode structure grown on Si(100). As a buried conducting layer and a top contact layer for metal contacts on each side of the double barrier structure, $\mathrm{B}$-doped $\mathrm{p}^{+} \mathrm{Ge}$ layers were epitaxially grown on $\mathrm{pSi}(100)$ by ultraclean low-pressure CVD using $\mathrm{GeH}_{4}, \mathrm{~B}_{2} \mathrm{H}_{6}$ and $\mathrm{H}_{2}$ gases [13]. After loading the $\mathrm{p}^{+} \mathrm{Ge} / \mathrm{pSi}(100)$ substrates into the flash-heating CVD reactor shown in Figure 1, a $200 \AA$-thick Ge buffer layer was grown by thermal decomposition of $\mathrm{GeH}_{4}$ at $350^{\circ} \mathrm{C}$. As a QW layer and a capping layer, pure Ge layers were formed under the condition shown in Figure 5 in which a single atomic layer of Ge was deposited on the Ge surface in every single flash light shot of $60 \mathrm{~J} / \mathrm{cm}^{2}$ at $260^{\circ} \mathrm{C}$. As a barrier layer, a $\mathrm{Si}_{1} \mathrm{Ge}_{1}$ atomic-layer superlattice was formed by depositing single atomic-layers of $\mathrm{Si}$ and $\mathrm{Ge}$ alternately at $275^{\circ} \mathrm{C}$, in which the $\mathrm{SiH}_{4}$ and $\mathrm{GeH}_{4}$ partial pressures were $500 \mathrm{~Pa}$ and the $\mathrm{SiH}_{4}$ and $\mathrm{GeH}_{4}$ exposure time were $20 \mathrm{~min}$ and $8 \mathrm{~min}$, respectively. For the $\mathrm{Ge}$ single atomic-layer growth on the Si surface, $\mathrm{GeH}_{4}$ exposure was stopped with the flash light shot of $60 \mathrm{~J} / \mathrm{cm}^{2}$ and the surface was finished by depositing a Ge atomic-layer for the growth of the QW and the capping layer. The diode structure was partially etched by using a CVD-SiO $\mathrm{S}_{2}$ mask and dilute $\mathrm{HF}-$ $\mathrm{H}_{2} \mathrm{O}_{2}-\mathrm{H}_{2} \mathrm{O}$ solution, and the etched surface was also passivated by $\mathrm{CVD}-\mathrm{SiO}_{2}$. Metal electrodes were formed by a sputtered $\mathrm{Al}-1 \% \mathrm{Si}$ alloy and no sintering was done to avoid $\mathrm{Al}$ spiking into the diode structure. In order to suppress an interdiffusion of $\mathrm{Si}$ and $\mathrm{Ge}$ at the hetero interface, all the fabrication processes during/after growing the diode structure were operated below $300^{\circ} \mathrm{C}$.

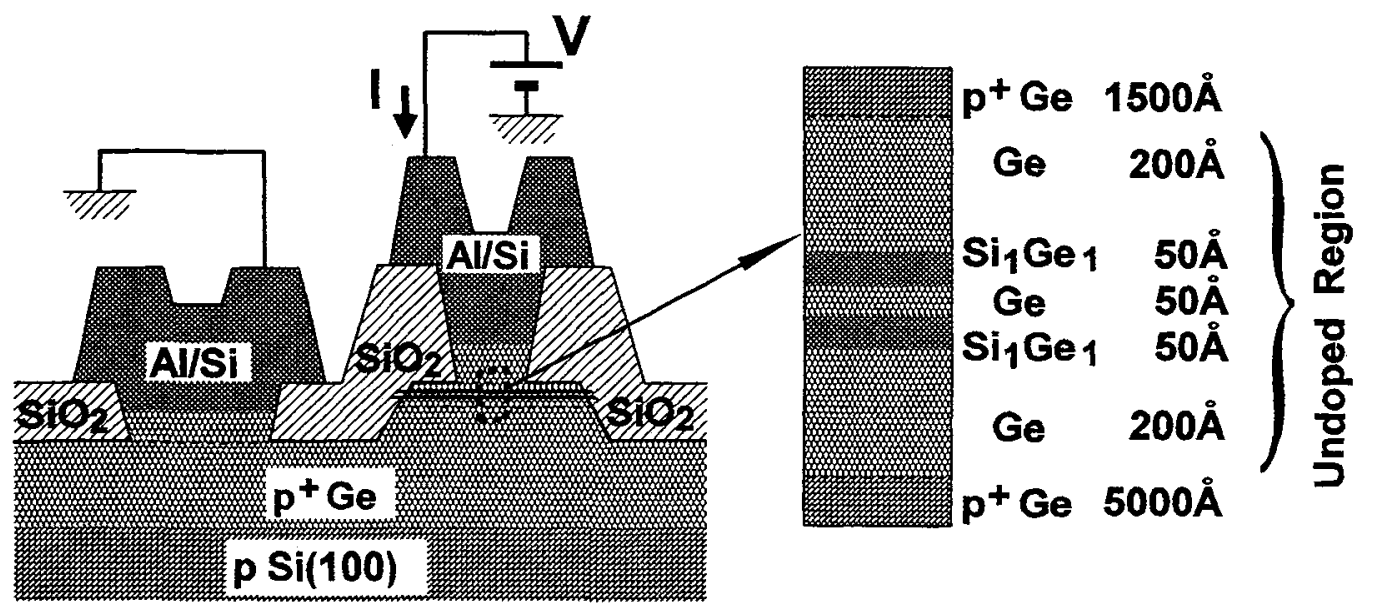

Figure 7: Schematic cross section of the resonant tunneling diode grown on $\mathrm{Si}(100)$. Inset shows the magnified view around resonant tunneling barriers. 


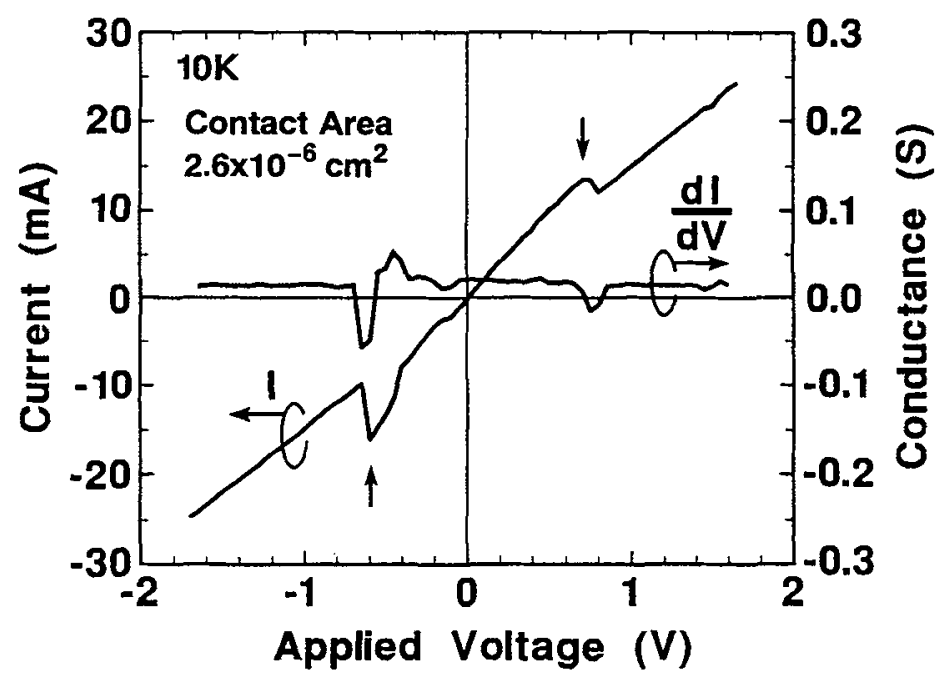

Figure 8: Current-voltage characteristic at $10 \mathrm{~K}$ for the resonant tunneling diode by using self-limited atomic layer-by-layer growth control method. Arrows indicate the peak position.

Here, as a most simplified approximation, we assume that the valence-band discontinuity $\left(\Delta E_{\mathrm{V}}\right)$ in $\mathrm{Si}_{1} \mathrm{Ge}_{1} / \mathrm{Ge}$ is the same as the calculated value in alloyed $\mathrm{Si}_{0.5} \mathrm{Ge}_{0.5} / \mathrm{Ge}$ [14]. Usually, tunneling probability of the light hole through the barriers is much larger than that of heavy hole. The bound state energy $\left(E_{\mathrm{LHO}}\right)$ was calculated to be $0.094 \mathrm{eV}$ from Schrödinger equation using $\Delta E_{\mathrm{V}}$ of $0.20 \mathrm{eV}$ for light hole(effective mass of $0.043 m_{0}\left(m_{0}\right.$ : electron mass in vacuum)) in Ge. Under uniform electric field approximation for the undoped region in a biased condition, resonant tunneling voltage $\left(V_{\mathrm{R}}\right)$ corresponding to $E_{\mathrm{LH} 0}$ was estimated to be $0.69 \mathrm{~V}$.

In the current-voltage characteristic shown in Figure 8 , two peaks are clearly observed in the Ge / $\mathrm{Si}_{1} \mathrm{Ge}_{1} / \mathrm{Ge} / \mathrm{Si}_{1} \mathrm{Ge}_{1} / \mathrm{Ge}$ system and they can be assigned to the resonant tunneling via the light-hole bound state in the Ge QW as calculated above. This suggests that the diode structure has an abrupt $\mathrm{Si}_{1} \mathrm{Ge}_{1} / \mathrm{Ge}$ interface due to employing a low-temperature atomic layer-by-layer growth process. In order to clarify the relationship between crystal quality and device characteristics, further investigation is needed.

\section{Acknowledgments}

The authors wish to express their thanks to Professors Shoichi Ono and Kuniyoshi Yokoo for their advice and encouragement in executing this study, and to Professors Nobuo Miyamoto, Maki Suemitsu and Hideo Ohno for their useful discussions. The CVD reactor was provided by Kokusai Electric Co., Ltd. This study was carried out in the Superclean Room of the Laboratory for Electronic Intelligent Systems, Research Institute of Electrical Communication, Tohoku University. This study was partially supported by a Grant-in-Aid for Scientific Research from the Ministry of Education, Science, and Culture of Japan. 


\section{References}

[1] Nishizawa J., Abe H. and Kurabayashi T., J. Electrochem. Soc. 132 (1985) 1197-1200.

[2] Nishizawa J., Aoki K., Suzuki S. and Kikichi K., J. Electrochem. Soc. 137 (1990) 1898-1904.

[3] Takahashi Y., Ishii H. and Fujinaga K., J. Electrochem. Soc. 136 (1989) 1826-1827.

[4] Takahashi Y. and Urisu T., "Self Limiting Adsorption of $\mathrm{SiCl}_{2} \mathrm{H}_{2}$ and Its Application to the Layerby-Layer Photochemical Process", Extended Abstracts of 1990 International Conference on Solid State Devices and Materials, Sendai, Japan, 1990 (The Japan Society of Applied Physics, Tokyo), pp.917-920.

[5] Murota J., Sakuraba M. and Ono S., Appl. Phys. Lett. 62 (1993) 2353-2355.

[6] Sakuraba M., Murota J. and Ono S., J. Phys. IV France, Colloque C3, 3 (1993) 449-456.

[7] Sakuraba M., Murota J., Mikoshiba N. and Ono S., J. Crystal Growth 115 (1991) 79-82.

[8] Murota J., Sakuraba M., Mikoshiba N. and Ono S., J. Phys. IV France, Colloque C1, 1 (1991) 803808.

[9] Kobayashi S., Cheng M. L., Kohlhase A., Sato T., Murota J. and Mikoshiba N., J. Crystal Growth 99 (1990) 259-262.

[10] Papagno L., Shen X. Y., Anderson J., Spagnolo G. S. and Lapeyre G. J., Phys. Rev. B 34 (1986) 7188-7191.

[11] Gupta P., Colvin V. L. and George S. M., Phys. Rev. B 37 (1988) 8234-8243.

[12] Ohtani N., Mokler S. M., Xie M. H., Zhang J. and Joyce B. A., Surf. Sci. 284 (1993) 305-31.4.

[13] Goto K., Murota J. and Ono S., Materials Science Forum 117-118 (1993) 153-158.

[14] Van de Walle C. G. and Martin R. M., Phys. Rev. B 34 (1986) 5621-5634. 